\title{
Sustentabilidade urbana: recuperação dos rios como um dos princípios da infraestrutura verde
}

\author{
Urban sustainability: recovery of rivers as one of the \\ principles of green infrastructure
}

\begin{abstract}
Maiara Roberta Santos Morsch
Juan José Mascaró

Adalberto Pandolfo

Resumo

$\mathbf{E}$

sta pesquisa apresenta uma abordagem a respeito da relação dos rios urbanos com as cidades com análise da situação atual desse recurso que historicamente foi elemento estruturador de muitas cidades brasileiras e atualmente se encontra em situação de abandono na maioria dos casos.

Objetivando apresentar uma proposta de alternativas para a requalificação urbanística de um rio urbano através da implantação da infraestrutura verde, o artigo desenvolve um estudo de caso que tem como tema o Rio Passo Fundo na cidade de Passo Fundo, Rio Grande do Sul. O procedimento metodológico foi estruturado em três etapas, em que primeiramente realizou-se a coleta de dados em gabinete e a escolha de um trecho do rio para aprofundamento do estudo. $\mathrm{Na}$ segunda etapa realizou-se a coleta dos dados físicos com identificação da situação atual do rio e seu entorno. Na terceira definiram-se diretrizes de requalificação do rio urbano. Ao final aplicaram-se as diretrizes no caso a fim de verificar a sua viabilidade, concluindo-se que as estratégias vão de encontro com o novo paradigma urbanístico. Com base na pesquisa desenvolvida indica-se que essas diretrizes serão válidas para casos semelhantes de requalificação urbanística de um rio urbano, o que possibilita a retomada dos rios de volta ao convívio social e equilíbrio ecológico.
\end{abstract}

Palavras-chave: Rios urbanos. Infraestrutura verde. Sustentabilidade urbana. Requalificação urbana.

Maiara Roberta Santos Morsch Universidade de Passo Fundo Passo Fundo - RS - Brasil

Juan José Mascaró Universidade de Passo Fundo Passo Fundo - RS - Brasil

Adalberto Pandolfo Universidade de Passo Fundo Passo Fundo - RS - Brasil

Recebido em 27/12/15 Aceito em 19/12/16

\section{Abstract}

This research presents an approach about the relationship between urban rivers and cities analysing the current situation of this resource that historically has been a structuring element of many Brazilian cities and is currently abandoned in most cases. Aiming to present a proposal of alternatives for the urban requalification of an urban river by implementing a green infrastructure, this paper develops a case study which focuses on the Passo Fundo river in the city of Passo Fundo, Rio Grande do Sul State. The methodological procedure was structured in three stages: first, the data collection was carried out in the office and a stretch of the river was chosen to study it in more depth. In the second stage, the physical data were collected identifying the current situation of the river and its surroundings. In the third step, we established the urban river requalification guidelines. Finally, we used the guidelines in the case in order to ensure its viability, concluding that the strategies are in line with the new urban paradigm. Based on the research developed, it is indicated that these guidelines will be valid for similar cases of urban requalification of an urban river, which allows for the resumption of the rivers back to social conviviality and ecological balance.

Keywords: Urban rivers. Green infrastructure. Urban sustainability. Urban regeneration. 


\section{Introdução}

Servindo como meio de circulação e fonte de recursos, os rios promoveram a sobrevivência das civilizações e estreitaram a relação do homem com a água. Os rios aparecem com frequência na formação e no desenvolvimento das cidades desempenhando um papel fundamental na estruturação das paisagens urbanas atuais (PORATH, 2003). Historicamente, o homem usufruiu dos seus recursos para posteriormente escondê-los na cidade, que cresceu sem dar-se conta da importância do potencial ecológico e ambiental de seus rios.

O crescimento urbano significou a destruição das características naturais que deleitam a alma humana (MUMFORD, 1998). A história das cidades e a falta de consciência dos cidadãos fazem com que vários dos rios urbanos pareçam lixeiras. A ausência de tratamento de esgoto e o descarte de poluentes industriais são os grandes responsáveis por essa situação. Abandonadas, as águas foram se tornando alvo de despejo de poluição e de ocupações irregulares e, onde a sua presença impossibilitava o desenvolvimento urbano, foram tampadas e esquecidas. Como resultado, os rios das cidades raramente são vistos conectados e vinculados a espaços verdes públicos, mas sim a fragmentação e a sobreposição dos sistemas de infraestrutura.

No século atual a cidade está passando por modificações profundas causadas pelo processo de globalização da economia, pelos modos de produção mundialmente interconectados e pela velocidade crescente das informações. $\mathrm{O}$ mundo precisa de novos horizontes para o urbanismo, de uma nova postura sustentável a respeito do ambiente urbano e natural que também focalizem a dimensão humana, com a perspectiva de que a humanidade poderá construir sem comprometer o meio natural. (GEHL, 2010; REGISTER, 1996; VEGARA, 2002).

Segundo dados da Comissão Mundial de Águas, 500 dos maiores rios do planeta enfrentam dificuldades com a poluição, porém existem várias cidades que transformaram seus rios degradados em belos retratos de cartão-postal, como a cidade de Taizhou, na costa leste da China, que em 2004 inaugurou um parque com uma abordagem sustentável ao longo do seu rio (ZEIN, 2014), e a cidade de Paris, na França que iniciou o processo de harmonização da tecnologia com a natureza em 2013, favorecendo o rio Sena e os pedestres (FONTENELLE, 2013).

Os rios urbanos possuem um alto potencial paisagístico e trazem benefícios às cidades que vão além da valorização da ambiência urbana. Assim, esta pesquisa fez uma abordagem a respeito da relação dos rios urbanos com as cidades com o objetivo de reunir alternativas para a requalificação desse recurso desestruturado inserindo-o na infraestrutura verde e convertendo-o em um espaço que permita reunir as pessoas.

A cidade de Passo Fundo, RS, objeto de estudo de caso, é banhada por um rio urbano que teve um importante papel na sua história e hoje se encontra degradado. Nessa cidade encontra-se também escassa disponibilidade de espaços verdes, descaso com os rios urbanos e pouco interesse para reverter esses problemas.

\section{Rio urbano versus cidade: um desafio para o novo urbanismo}

A maior parte das cidades brasileiras surgiu às margens dos rios, o que revela o seu importante papel histórico. O homem modifica a natureza para atender suas necessidades da vida cotidiana. A ação humana foi no sentido de dominá-lo, procurando conter o rio, sufocando-o e suprimindo-o da superfície urbana (HERZOG, 2013). Com o tempo os rios urbanos foram sendo ofuscados por intervenções sem critério e hoje têm a sua identidade escondida, cancelando os traços deixados pelo tempo passado e perdendo sua forma e morfologia original.

O abandono dos rios é uma realidade, os que antes eram elementos estruturadores acabaram ficando em segundo plano no meio urbano e hoje são mal compreendidos. Tratados como limitadores de crescimento, quando não são canalizados, os rios são alvo de despejo, poluição e moradias irregulares (PORATH, 2003). Raramente vemos a hidrografia de nossas cidades vinculada a parques e espaços verdes, o que acontece é a sobreposição dos sistemas de infraestrutura tradicional. Sob os aspectos físicos, os rios são elementos importantes da cidade, podendo enriquecer a construção da paisagem urbana. Em paralelo, é cada vez mais visível a falta de áreas verdes e de espaços públicos que assegurem a qualidade de vida, o lazer e a socialização dos indivíduos nas cidades.

Reintegrar os rios urbanos na paisagem e fornecer uma relação humana com a água de forma includente são desafios para as cidades brasileiras. Essa revitalização fortalece a cultura local e ainda devolve parte da natureza pertencente ao território para o desfrute de todos. Revelar os rios em meio à cidade é buscar uma volta ao passado, é retomar uma cultura que está na memória coletiva. É dar oportunidade à população de participar da cidade, 
de unir os fragmentos deixados pelo século passado.

Em trabalho realizado para a Bacia Urbana do Alto Tietê, em São Paulo, Pellegrino et al. (2006) concluem que um programa de recuperação ambiental e de paisagem da água urbana avança além do nível da estética paisagística, fomenta a sustentabilidade socioambiental por meio desses espaços abertos transformando os espaços públicos locais e com isso promove a exploração de um novo paradigma, que alia a drenagem das águas com a recuperação dos ecossistemas locais e a qualidade de vida urbana.

E é nessa procura de enfrentar os problemas da atualidade, buscando dimensões mais humanas e mais ecológicas, que se objetiva o estudo da infraestrutura verde e a sua relação com o ambiente construído. Especificamente para os rios urbanos, que hoje se encontram em situação de abandono, é que se busca resgatar a expressiva relação da comunidade com a água dando-lhe valor na cidade como um importante elemento natural, cultural e patrimonial através da qualificação urbana com a implantação de infraestrutura verde.

O ambiente natural se altera no meio urbano, mas é possível que ambos vivam em harmonia. $\mathrm{Na}$ atualidade podem-se encontrar diversos casos em que cidades retomam às suas origens renaturalizando rios e devolvendo a eles a sua importância. Após ter caído no esquecimento, os rios e o seu entorno ganham uma revitalização reconfigurando as suas relações com a cidade e áreas decadentes são convertidas em lugares atrativos de desenvolvimento urbano.

Os rios urbanos possuem um alto potencial paisagístico e podem trazer benefícios às cidades que vão além da valorização do desenho urbano. Segundo Porath (2003), os rios podem ser um problema ou se tornarem a solução paisagística na cidade. Ao tratar os rios como parte da infraestrutura verde pode-se olhar para um novo horizonte e assim encontrar um caminho ao qual a água volta a se conectar com o homem e ganhar uma relação de harmonia com a cidade.

\section{A infraestrutura verde e os rios urbanos}

Os estudos a respeito dos espaços urbanos buscam entender as diversas funções que estes adquirem no cotidiano das cidades, relacionando-os às suas dimensões físicas territoriais e socioculturais. Sabe-se que a qualidade de vida urbana é garantida pela existência de um adequado sistema de espaços públicos livres de lazer, sendo importante que a quantidade desses espaços seja compatível com o número de habitantes da cidade e que seja distribuída na malha urbana de maneira acessível a toda a população (OLIVEIRA; MASCARÓ, 2007).

A infraestrutura verde é indispensável para a renovação do urbanismo e para a retomada dos serviços essenciais prestados pela natureza que equivalem à maioria das funções da infraestrutura tradicional. A infraestrutura verde é fundamental no desenvolvimento sustentável das cidades em várias escalas, engloba um conceito contemporâneo e visa estabelecer uma conexão da cidade com os elementos naturais. Esse conceito se define como de redes multifuncionais de espaços vegetados, arborizados e permeáveis, espaços públicos e privados que, interconectados, reestruturam a paisagem. Essa rede, que engloba os aspectos sociais, ambientais e econômicos, dá suporte à vida e visa ações voltadas a manter ou reestabelecer os processos naturais do meio e assegurar a qualidade de vida urbana (BENEDICT; MCMAHON, 2004). A rede de infraestrutura verde inclui uma ampla variedade de elementos, como corredores verdes, parques, ruas e praças, e nem sempre eles estão relacionados à proteção dos sistemas naturais. Também inclui áreas que beneficiam as pessoas, como trilhas, áreas de lazer, mirantes, fazendas, etc. (BENEDICT; MCMAHON, 2006).

Os corredores verdes são espaços livres que conectam áreas naturais, formando corredores lineares que compõem o conceito de sustentabilidade. São planejados para fins ecológicos, recreativos, culturais estéticos e produtivos, e são capazes de requalificar ambientalmente os territórios degradados reestruturando o tecido urbano, a paisagem e contribuindo para a interação das pessoas com o meio natural. É um meio ecológico que serve de hábitat para a flora e fauna além de contribuir para a drenagem urbana. Entre suas diversas classificações encontra-se o "corredor verde fluvial”, que se forma ao longo das águas urbanas promovendo naturalmente a redescoberta dos rios negligenciados (LITTLE, 1990; MINKS, 2013).

Dentro do mesmo conceito as ruas verdes são ruas arborizadas que contemplam um projeto holístico e multifuncional adequado à paisagem local. Realizam o manejo das águas pluviais reduzindo o escoamento superficial e a poluição difusa. Nelas o tráfego de veículos é menos intenso, priorizando o pedestre com sinalização visual e física. Têm o potencial de conectar áreas verdes e de melhorar a qualidade dos espaços urbanos, aumentando a conexão das pessoas com as áreas verdes (HERZOG, 2010). 
Alguns importantes componentes das ruas e corredores verdes são: os jardins de chuva que, segundo Herzog (2013), consistem em ecossistemas artificiais que recebem águas de chuva de superfícies adjacentes e entre seus benefícios estão a retenção e filtragem da água e a diminuição do escoamento superficial; os alagados construídos que recebem águas contaminadas e modificam a sua qualidade, promovendo a retenção e remoção de seus contaminantes e a consequente purificação da água (HERZOG, 2013); os jardins aquáticos compostos de plantas filtrantes que, por meio da fotossíntese, possuem a função de oxigenar e purificar águas contaminadas restaurando rios e lagos e aumentando a biodiversidade com a criação de um hábitat para micro-organismos benéficos (ABELSON; DANKO, 2013; YONG; TAN, 2014); e os pavimentos permeáveis, também chamados de pavimentos porosos ou drenantes, que permitem a infiltração das águas reduzindo a impermeabilidade das superfícies urbanas e as inundações das cidades, dentre eles existem diversas tecnologias usuais, como o asfalto poroso e o piso intertravado de concreto (MARCHIONI; SILVA, 2011).

Criar essa rede implica buscar as oportunidades existentes. As redes de infraestrutura verde são projetadas a partir do sistema hídrico de águas e de drenagem, fazendo a conexão de áreas vegetadas para manter e reestabelecer a ecologia (BENEDICT; MCMAHON, 2006). Assim, a rede verde transforma áreas densamente habitadas em espaços agradáveis e atrativos, e também oferece uma oportunidade de estabelecer e manter uma relação cotidiana do homem com a natureza, o que possibilita educar ambientalmente um maior número de pessoas. Considerando que os sistemas naturais também englobam rios e córregos, deve ser garantido aos rios que exerçam suas funções ecológicas no território urbano, vitais para a sua sustentabilidade, através de uma conectividade dessa infraestrutura formando uma estrutura ecológica urbana (FERREIRA; MACHADO, 2010).

Mell (2017) aponta que Paris tem investido amplamente em infraestrutura verde, que é atraente e eficiente, pois pode reagir a mudanças e se adaptar a necessidades urbanas. Pode ser vista como uma forma de revalorização dos espaços a curto e longo prazo. Segundo o autor, com o exemplo da integração do rio Sena e a rede verde, essas alterações no tecido urbano podem levar a novas potenciais formas de desenvolvimento. $\mathrm{O}$ jardim flutuante implantado nas margens do rio, perto da Torre Eiffel, é um exemplo de infraestrutura verde. Possui $1.800 \mathrm{~m}^{2}$ em cinco ilhas flutuantes feitas em estrutura metálica acessíveis a todos e compostas de plantas aquáticas e gramíneas que, por meio de sua fotossíntese, cumprem o papel de manter a água do rio limpa.

Em Portugal, a cidade de Agualva-Cacém mudou o curso de sua história entre os anos de 2001 e 2009. Com uma atuação estratégica e aprofundada sobre o espaço público, a cidade realizou intervenções integradas de reformulação das acessibilidades internas e interligação com centralidades envolventes, valorizando os elementos naturais estruturantes da cidade. A intervenção central foi a requalificação do sistema ambiental criado pela Ribeira das Jardas em articulação com os parques verdes, transformando em canal verde - parque linear - e promovendo o equilíbrio ecológico da cidade. Além de paisagismo, drenagem, iluminação e plantações, ainda foi inserida a regularização fluvial em todo o percurso do rio através da inserção de patamares de contenção da água e a aproximação das pessoas (COELHO, 2012) (Figura 1).

Figura 1 - A rede verde no rio urbano de Agualva-Cacém

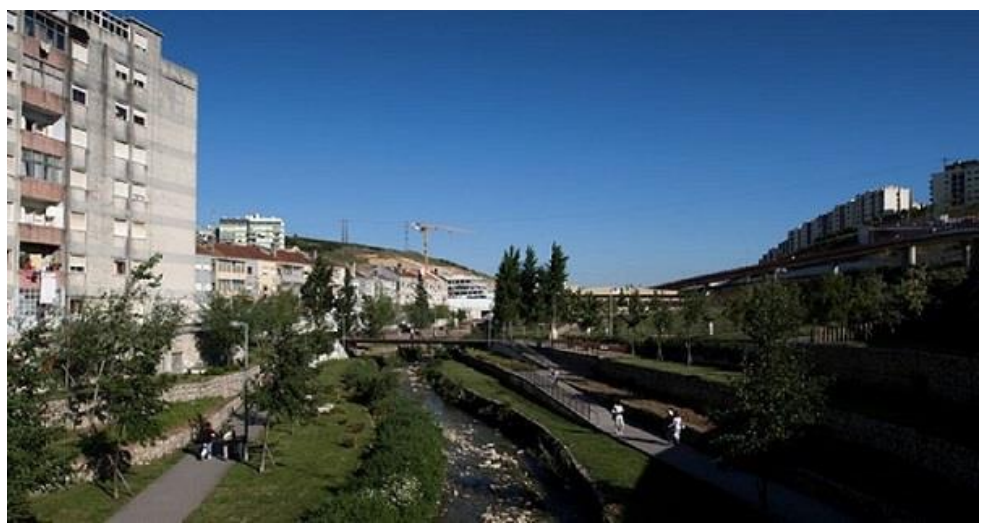

Fonte: Risco (2015). 
Outra cidade que inseriu infraestrutura verde ao seu rio foi Seul, na Coreia do Sul. O país possui um plano estratégico de crescimento verde que tem como visão "Reviver os rios para a nova Coreia!". $\mathrm{O}$ rio CheongGyeCheon, antes canalizado sob vias de veículos, hoje é o elemento estruturador de áreas prioritárias para pedestres. Seul retirou as vias, restaurou o córrego e o devolveu à população um corredor verde em suas margens situadas entre três e cinco metros abaixo do nível da rua.

Segundo Lee (2006), depois da obra terminada foi realizado um levantamento de dados no local, onde se constatou melhora na qualidade do ar em cerca de $30 \%$, redução do nível de ruído, redução do efeito ilha de calor e criação de um corredor de vento. A biodiversidade também deu um salto, agora existem no local 14 espécies de peixes, 18 espécies de pássaros, 41 espécies de insetos. Além disso, o local ganhou vitalidade econômica, preferência para pedestres, harmonia entre o desenvolvimento e a preservação, mudanças do paradigma da gestão urbana, restauração histórica e ecológica.

O objetivo geral da pesquisa realizada é contribuir para o desenvolvimento de metodologias de qualificação urbana sustentável através da compilação de diretrizes para a recuperação e revitalização dos rios esquecidos no meio urbano como parte das estratégias de aplicação dos conceitos da infraestrutura verde a partir do estudo de caso do Rio Passo Fundo, na cidade de Passo Fundo, RS.

\section{Método}

Os procedimentos desenvolvidos foram realizados em etapas.

\section{Revisão bibliográfica}

Com vistas a embasar teoricamente a pesquisa a ser desenvolvida, reúne-se uma revisão bibliográfica de assuntos referentes ao tema do projeto. Para compreender o desenvolvimento urbano atual é necessário entender as cidades e seu crescimento, o que é feito por meio da análise do Censo IBGE 2010 (INSTITUTO..., 2014). A relação da cidade com a natureza, com os rios, é estudada em Porath (2003). Um apanhado histórico da configuração do espaço urbano nas cidades, em especial a de Passo Fundo, e a sua relação com o homem e com a natureza mostra o porquê da atual situação de descaso com a conservação dos recursos naturais, que incluem os rios urbanos, segundo os autores Mumford (1998), Le Corbusier (2004), Richard Register (1996), Herzog (2013), Silva e Romero (2011), Vegara
(2002), Gehl (2010), Coy (2013), Pellegrino et al. (2006), Los Angeles (2014), Plataforma Urbana (2014), Fontenelle (2013). Para adotar uma definição de cidade de porte médio foram usados os critérios propostos por Braga (2005), Maricato (2001) e Brito, Horta e Amaral (2001). Esses referenciais, juntamente com a conceituação acerca da infraestrutura verde e como ela pode qualificar ambientalmente e socialmente os rios urbanos, contextualizam este texto.

A revisão da bibliográfica foi complementada com a análise dos registros encontrados do Rio Passo Fundo, bem como da cidade desde a sua formação. Coletou-se dados existentes, como documentos municipais específicos do Rio Passo Fundo e de sua bacia hidrográfica, que foram úteis ao diagnóstico da área e ao aprofundamento do estudo. As informações foram coletadas no Comitê de Gerenciamento da Bacia Hidrográfica do Rio Passo Fundo (CBHPF) (COMITÊ..., 2014).

\section{Levantamento e análise de informações do Rio Passo Fundo e escolha de um trecho para estudo}

Foi realizada uma análise dos registros encontrados do Rio Passo Fundo bem como da cidade desde a sua formação. Coletou-se dados existentes como documentos municipais específicos do Rio Passo Fundo e de sua bacia hidrográfica, que foram úteis ao diagnóstico da área e ao aprofundamento do estudo. As informações foram coletadas no CBHPF, tomando-se conhecimento de suas ações e documentações. Posteriormente buscou-se as secretarias de Planejamento Urbano e de Meio Ambiente na Prefeitura Municipal, para obter os dados do rio na malha urbana. Também foram utilizados dados de bibliografias complementares e de outras pesquisas relacionadas.

Nesta etapa foram encontrados materiais relevantes para o conhecimento dos condicionantes atuais da área. Os dados históricos do rio em estudo mostraram a sua ligação com a formação da cidade, bem como o comportamento da cidade em relação com o rio ao longo do seu desenvolvimento até os dias de hoje. O mapeamento e levantamento das condições físico/químicas da bacia hidrográfica trouxeram a realidade do que ocorre em cada trecho do rio da sua nascente, zona rural, ao trajeto de entrada e saída da cidade. Com esse procedimento conseguiu-se mapear onde as ações devem ocorrer para adequar a requalificação urbanística do rio em estudo. O mapeamento e levantamento das condições físico/químicas do rio apresentaram a situação atual do rio que percorre a área 
urbanizada, sua relação com o entorno e com as questões legais do plano diretor. Apresenta-se a arborização ribeirinha existente, os dados da qualidade da água em diversos pontos, bem como as ações que estão sendo realizadas para o seu manejo.

A partir dessas informações, desenvolveram-se critérios baseados nos dados coletados sobre o rio e em aspectos estudados na revisão bibliográfica. Assim, o trecho escolhido para estudo, que compreende $1.600 \mathrm{~m}$, é o que apresenta a maior necessidade de intervenções urbanas. Como demonstra o mapa da Figura 2, o trecho localiza-se em área centralizada na cidade, junto à principal avenida.

\section{Levantamento físico da área de intervenção}

A fim de não se limitar a solucionar problemas pontuais considerou-se a importância de uma visão global da toda a área de estudo, que se estende por $1.600 \mathrm{~m}$ delimitados pela Avenida Sete de Setembro à sul (limite direito no mapada Figura 3) e pela rede ferroviária à norte (limite esquerdo no mapada Figura 3). A realização do levantamento decorreu com visitas ao local onde a área foi percorrida identificando a sua configuração no espaço urbano através de registros fotográficos, observação e entrevistas.

Primeiramente foram identificados os usos e a ocupação do entorno. $\mathrm{Na}$ área foram encontrados usos residencial, comercial e misto, serviços públicos e igrejas, que contribuem para a sua densa ocupação, apesar de se identificar também vazios urbanos junto ao rio. Em relação à área de preservação foram identificadas inserções de edificações de todo tipo de usos, incluindo edificações de grande porte regularizadas, como um hipermercado. Além disso, foram identificadas ruas avançando na área de preservação ambiental (APP).

Devido à sua grande extensão, dividiu-se o trecho em 4 parcelas, separadas por terem configurações semelhantes quanto ao uso e ocupação do solo. Foram designadas como "trecho A", "trecho B", "trecho C" e "trecho D", como mostra a Figura 3. Em cada trecho foram selecionados dois pontoschave para a caracterização das suas características físicas.

\section{Elaboração das diretrizes}

A partir dos estudos realizados em gabinete e em campo foram definidas as sete temáticas importantes para a revitalização de um rio urbano. Para cada tema foram traçados objetivos que deram respaldo às diretrizes visando cumprir atribuições em diversas escalas urbanas do caso em estudo. Essas diretrizes trazem soluções de infraestrutura verde e soluções complementares que também podem servir para a aplicação em outras cidades em situação semelhante à de Passo Fundo. Como forma de exemplificação e verificação da viabilidade das diretrizes propostas realizou-se uma simulação inserindo-as no caso estudado.

\section{Figura 2 - Mapa de Passo Fundo}

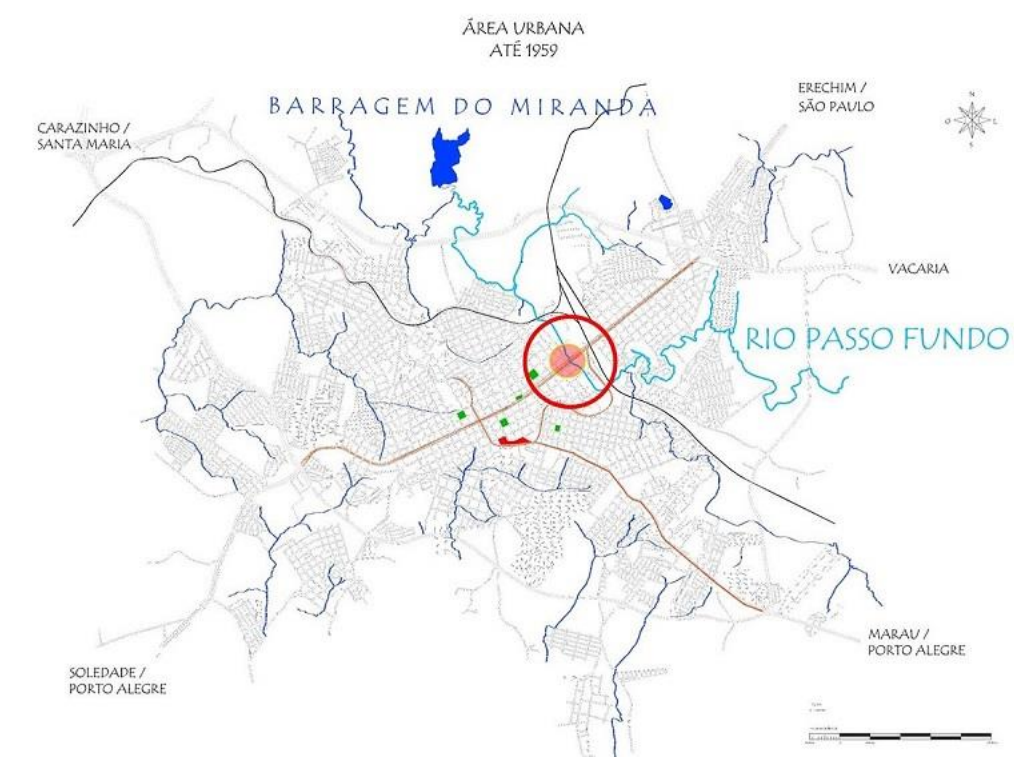

Fonte: adaptado de Prefeitura Municipal de Passo Fundo (2015). 
Figura 3 - Divisão da área de estudo

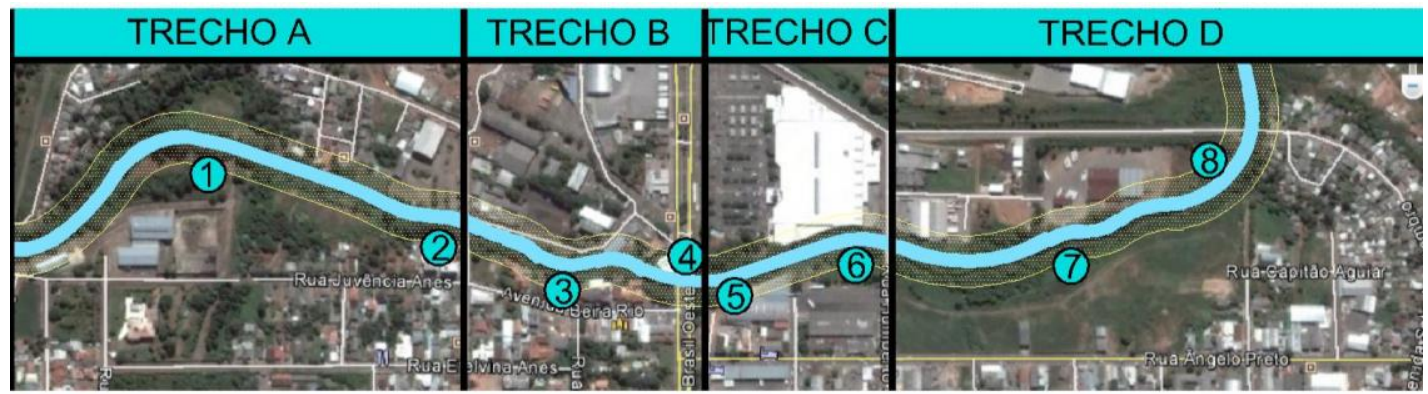

Fonte: adaptado de Google Earth (2015).

\section{Análise de resultados}

\section{Proposta para a cidade média}

Ao serem analisadas as ações urbanas relacionadas ao desenvolvimento sustentável através da implantação de infraestrutura verde e da integração da população com a cidade e com a natureza, foram encontradas iniciativas principalmente em cidades de grande porte. Em contrapartida, as cidades de porte médio brasileiras estão em desenvolvimento e avançam no território nacional, tanto demográfica como economicamente, e configuram novos arranjos espaciais nas regiões em que estão inseridas, e é justamente nessas cidades que se encontra escassa disponibilidade de espaços verdes e o descaso com os rios urbanos. Embora alguns autores apontem que as cidades brasileiras de porte médio são os municípios cuja população urbana situa-se entre $100 \mathrm{mil}$ e $500 \mathrm{mil}$ habitantes, não existe uma ideia consensual e uma definição cristalizada do que seriam cidades médias, todavia essas cidades desempenham um papel primordial no desenvolvimento regional, e têm um papel de articuladoras privilegiadas, onde se desenvolvem os polos tecnológicos e as redes de todos os tipos (ANDRADE; SERRA, 2001; AMORIM FILHO; SERRA, 2001; BRAGA, 2005; BRITO; HORTA; AMARAL, 2001; MARICATO, 2001).

É o caso da cidade de Passo Fundo, que está localizada no estado do Rio Grande do Sul e se insere em uma área municipal de $783,421 \mathrm{~km}^{2}$, com uma população de 184.826 habitantes. É classificada como cidade média e polo de desenvolvimento socioeconômico regional. Seu elevado índice de urbanização chega a 97,45\% da população concentrada na área urbana, ocasionado pelo crescimento desordenado ocorrido principalmente na década de 1970, o que gerou reflexos negativos ao meio ambiente, principalmente junto às áreas de preservação permanente de importantes mananciais hídricos (INSTITUTO..., 2014).
Historicamente o Rio Passo Fundo foi testemunha de todos os momentos marcantes do município e constituiu também um local de lazer na década de 1940, as águas eram límpidas e cristalinas, as sombras agradáveis, a vegetação exuberante e aconchegante (MELO, 1998). Atualmente o Rio Passo Fundo possui uma extensão total dentro do município de $52,5 \mathrm{~km}$, com 3,9 km de extensão no perímetro urbano. Ele é o rio mais importante que corta a malha urbana. De acordo com Corazza (2008) 60\% do Rio Passo Fundo encontra-se canalizado e, juntamente com a canalização, houve o aterro de seu leito. Em muitos pontos a drenagem é ineficiente, o que ocasiona alagamentos durante as chuvas. $\mathrm{Na}$ maioria dos locais em que não há canalização, as áreas de preservação permanente ao longo do leito estão ocupadas irregularmente, principalmente por residências que lançam o esgoto sem tratamento nos corpos d'água e contribuem para o acúmulo de resíduos sólidos no rio.

Segundo a Fundação Estadual de Proteção Ambiental (Fepam) (FUNDAÇÃO..., 2014) a sua bacia hidrográfica faz parte da Região Hidrográfica do Uruguai, que abrange a porção norte, noroeste e oeste do território sul-riograndense. As principais atividades econômicas desenvolvidas estão relacionadas com a agricultura e a pecuária, destacando-se as culturas de soja e milho. A região enfrenta problemas ambientais, podendo se destacar a descarga de esgotos sem tratamento nos corpos hídricos, cargas de efluentes de dejetos de aves e suínos e de efluentes industriais sem tratamento, uso indiscriminado de agrotóxicos, desmatamento ao longo dos cursos d'água (matas ciliares), disposição inadequada de resíduos sólidos urbanos, etc. A Bacia do Rio Passo Fundo abrange 30 municípios, e o mais populoso é Passo Fundo (FUNDAÇÃO..., 2014).

O CBHPF realizou o diagnóstico da área e detectou poluição já acarretada antes do rio chegar ao meio urbano, advinda das atividades agropecuárias desenvolvidas na região. Já a 
poluição do rio na área urbana é mais intensa e oriunda de esgotos domésticos destinados no leito do rio sem nenhum tratamento e também do despejo de lixo no local. A recomendação é para a criação de estratégias para a recuperação do rio, mas para isso é necessária a mobilização da sociedade.

\section{O caso do Rio Passo Fundo}

O levantamento no local serviu para identificar a situação da área de estudo. O trecho A possui uma característica residencial com predominância de alturas de um a quatro pavimentos e com a preservação do rio e da sua APP no miolo da superquadra que o envolve, onde ocorre um uso agrícola privado. Tal uso é inadequado no meio urbano da maneira que se propõe. A situação atual dessa região deixa o rio escondido e em situação de abandono, o que, apesar de preservá-lo fisicamente, ignora a relação homem versus natureza e não traz benefícios para a população do entorno. Pelo contrário, a população sofre com uma área de instabilidade e insegurança (Figura 4).

O trecho B compreende uma área no bairro Centro, com uso misto residencial, comercial e de serviços que vão de um a dois pavimentos. Em alguns trechos edificações invadem a APP e em outro uma importante via faz esse papel percorrendo paralelamente ao rio. Apesar do inadequado impacto ambiental causado pelas ocupações na
APP e pela impermeabilização do solo, é nessa estreita faixa vegetada (entre o rio e a via) que se observou a melhor relação do rio com a cidade. A área verde no seu entorno passa uma sensação de segurança e tranquilidade no local. Em ambos os locais foram encontradas a presença de lixo e canalizações de efluentes desaguando no rio (Figura 5).

No trecho $\mathrm{C}$ o curso do rio passa em fundo de lotes, onde a APP é invadida por edificações consolidadas de uso misto, serviço e comerciais impermeabilizando o solo. A predominância de altura das edificações é de três e quatro pavimentos. No local também foi encontrada a presença de lixo. É uma área menos abandonada que as anteriores, apesar de não ser uma área acessível para a população devido às apropriações irregulares (Figura 6).

No trecho $\mathrm{D}$ o rio também se configura como fundo de lotes em miolo de quadra, passando despercebido no dia a dia da população. Aqui existem poucas edificações térreas consolidadas na APP, mas sim uma grande área verde murada, que possui um grande potencial para a implantação de uma área verde, trazendo dessa forma a proximidade da população com a natureza e com o rio, além de proporcionar o aumento de espaços públicos de lazer que atualmente a cidade carece, conforme a Figura 7

Figura 4 - Seção transversal esquemática do trecho A e fotografia do local

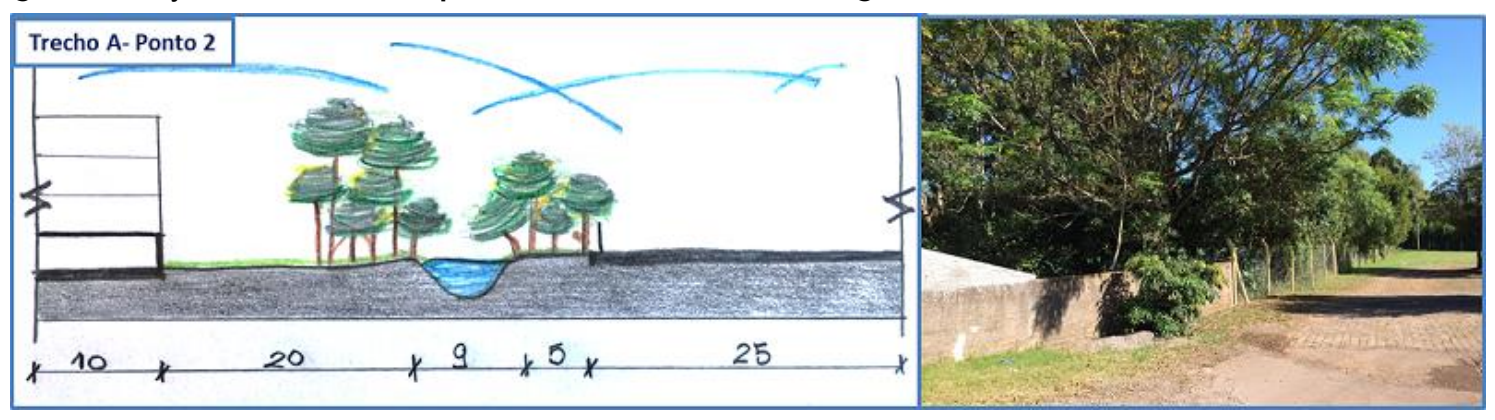

Nota: *medidas em metros.

Figura 5 - Seção transversal esquemática do trecho B e fotografia do local

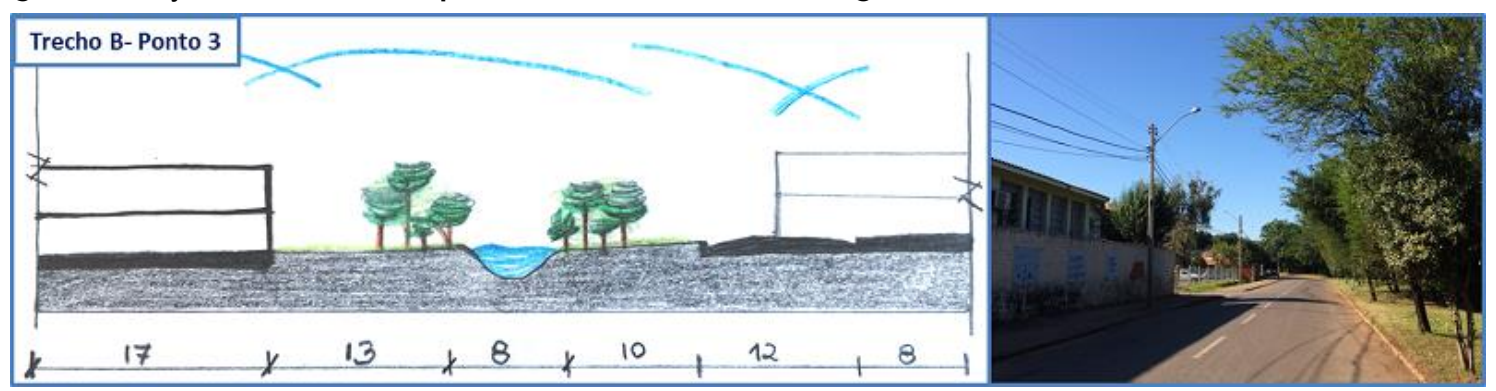

Nota: *medidas em metros. 
Figura 6 - Seção transversal esquemática do trecho $C$ e fotografia do local

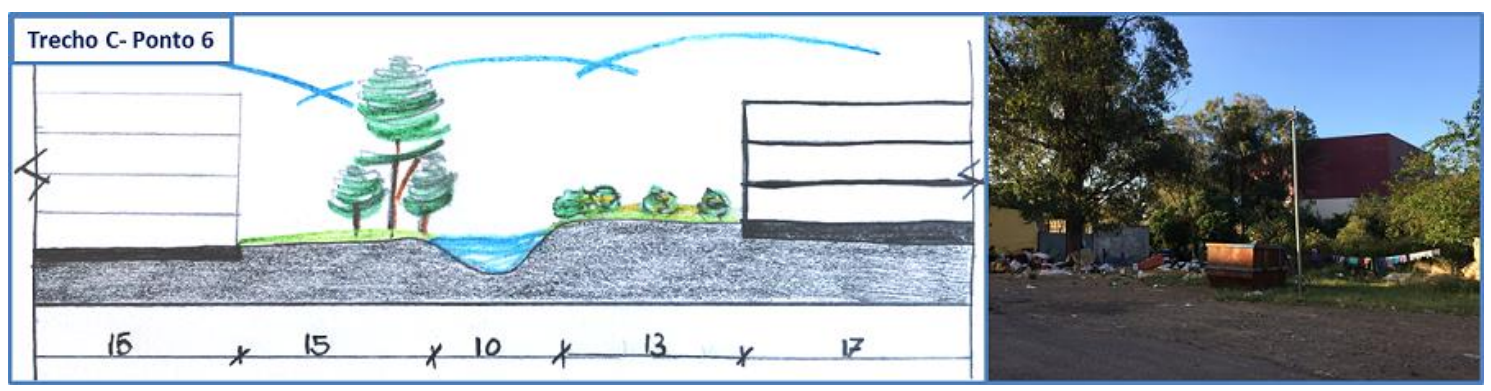

Nota: *medidas em metros.

Figura 7 - Seção transversal esquemática do trecho D e fotografia do local

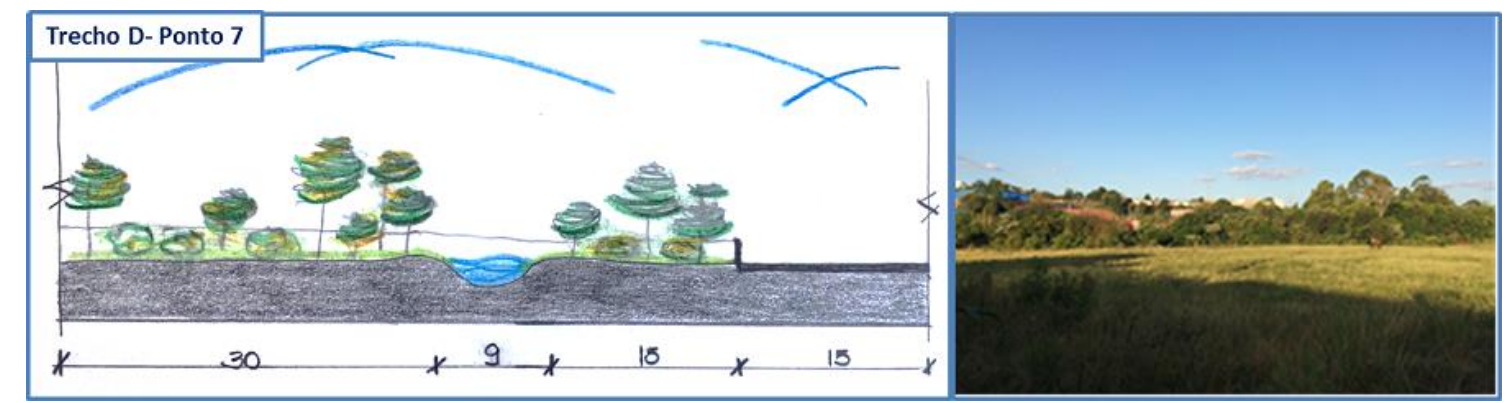

Nota: *medidas em metros.

Assim, o levantamento e a observação de campo mostram um rio que corre em fundos de lotes. Ao contrário da vegetação que se apresenta de forma semelhante ao longo do trecho, apresentando arborização de pequeno, médio e grande porte, há uma heterogeneidade de características nas margens do rio, como grandes vazios urbanos, habitações irregulares, equipamentos de serviços e edificações comerciais consolidadas. Observa-se que a característica mais forte do rio é a situação de abandono e indiferença. Ainda que ações estejam sendo realizadas pelo poder público, há uma carência de ações preventivas que tragam uma consciência ambiental e a proximidade da população com o meio natural.

\section{Diretrizes de intervenção}

As cidades contemporâneas visam soluções para o desenvolvimento sustentável através da busca pela dimensão humana e social. É essencial propiciar à população áreas de lazer, assim como preservar a natureza, aproveitando o espaço que ela oferece com ações planejadas que não afetem o ecossistema e que estabilizem os conflitos sociais, políticos e ambientais que a humanidade enfrenta atualmente (MARTINELLO; PETRY, 2013). A rede verde é um tipo de infraestrutura que é crítica para a continuidade e o crescimento de uma comunidade. Ela é parte dos sistemas de suporte da vida natural, um critério de interconexão de rios, terras úmidas, bosques, hábitats selvagens e outras áreas naturais; sendas verdes, parques e outras áreas de conservação; espaços abertos que suportam espécies nativas, mantêm o processo ecológico natural, sustentam recursos de ar e água e contribuem para a qualidade de vida e a saúde das pessoas (AHERN, 2003; GUELL, 2006).

Segundo o manual europeu de requalificação dos ecossistemas aquáticos (BRACHET; THALMEINEROVA, 2015), a restauração das águas refere-se a uma variedade de medidas e práticas que variam em tamanho e complexidade, destinadas a restaurar o funcionamento natural do rio e a permitir os seus usos sustentáveis e multifuncionais, portanto a restauração do rio faz parte da gestão sustentável da água. Segundo o documento, é de suma importância definir objetivos do projeto de intervenção para viabilizar o seu planejamento e também atender as necessidades de todas as partes interessadas, como o setor público e privado, políticos, profissionais, cientistas e os cidadãos afetados.

A requalificação dos rios tem que ser colocada em prática com adoção de critérios de intervenção que venham a sanar os problemas típicos como o desrespeito, a poluição, a falta de consciência da população e a escassez de áreas verdes. Para alcançar os objetivos, as intervenções devem ser feitas em grande escala e também em ações pontuais. É importante frisar que tais alternativas devem levar em consideração a viabilidade econômica e social buscando um equilíbrio entre a 
situação existente do local e o que seria o ideal, viabilizando a sua implantação. As diretrizes foram traçadas para diferentes proposições e seus respectivos objetivos e posteriormente foram inseridas no caso de forma a exemplificar uma maneira de apropriação e verificar a sua viabilidade.

\section{Ecologia e Biologia}

Objetivo: potencializar os aspectos da paisagem da orla e reestabelecer a diversidade ecológica ao longo do rio, seja no hábitat aquático ou terrestre.

Diretrizes: preservar e recriar a paisagem natural do entorno do rio e estabelecer áreas de transição entre o meio urbano construído e o meio natural criando um hábitat para os seres vivos no meio urbano.

Mesmo que a largura de $30 \mathrm{~m}$ de área de preservação permanente não tenha sido respeitada por algum motivo, ou tenha sua vegetação suprimida, é importante criar mecanismos vegetais para manter a diversidade ecológica no entorno do rio a fim de atrair a fauna e a flora para dar suporte a sua manutenção e recuperação. A recuperação da vegetação nativa ribeirinha e a inserção de ruas verdes formando um corredor verde conector das áreas vegetadas são estratégias que viriam a cumprir essa demanda, como ilustra a Figura 8.

\section{Gestão da água}

Objetivo: preservar a qualidade da água desde a nascente promovendo o tratamento e mantendo a qualidade da água no meio urbano.

Diretrizes: (a) proteger o curso d'água evitando a sua contaminação por pesticidas e agrotóxicos em áreas agrícolas;

(b) implantar métodos que busquem o tratamento das águas residuais antes de serem lançadas em seu leito e também do próprio rio; e

(c) impedir o depósito de lixo em suas margens.

Alcançar a qualidade da água é a proposição mais significativa para o rio. Por se tratar de um elemento natural, a proposta deve partir de estratégias de infraestrutura verde aplicando sistemas naturais de tratamento, como os jardins aquáticos compostos de plantas filtrantes, ilustrados na Figura 9. Dependendo da situação em que se encontra podem ser alternativas mitigatórias e até suficientes para tratar o rio. É indicado identificar os despejos ao longo de seu percurso para se fazer a implantação de uma rede coletora para tratamento do esgoto. Além disso, deve-se impedir a disposição de lixo no rio e em seu entorno através da inserção de locais adequados para o seu depósito e também de atividades de educação da população.

\section{Morfologia e drenagem}

Objetivo: proteger a função do rio, resgatar e alavancar a sua morfologia, dar ênfase para a área de preservação permanente e aumentar a permeabilidade em seu entorno.

Diretrizes: recuperar a área de proteção permanente degradada e preservar a existente removendo ocupações irregulares quando viável, permeando o solo e dando suporte à época de cheias com elevações do nível da água.

Figura 8 - Rua verde permeável transversal ao rio urbano

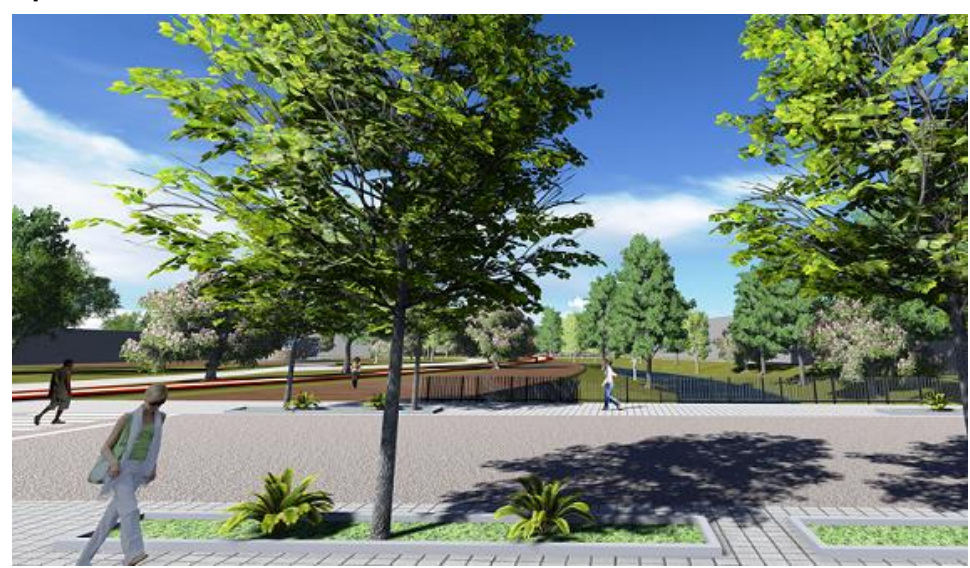

314 Morsch, M. R. S.; Mascaró, J. J.; Pandolfo, A. 
Figura 9 - Jardim aquático flutuante atuando no rio urbano

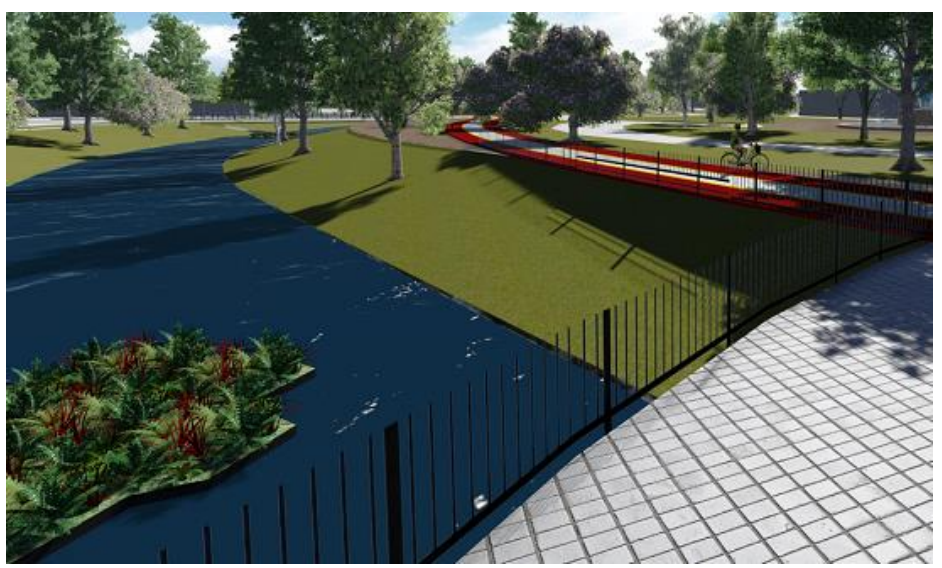

A APP serve para proteger a função do rio, porém não é raro o desrespeito da área de preservação no meio urbano, por isso é importante buscar maneiras para recriar a permeabilidade do solo, as áreas vegetais e preservar a morfologia do rio, ou recriá-la quando esta estiver modificada. A remoção de ocupações estabelecidas nem sempre é possível, nesse caso tem-se como segunda alternativa a inserção de tetos e/ou paredes verdes nessas edificações. Os jardins de chuva e os pavimentos permeáveis possibilitam a infiltração de águas pluviais pelo solo, evitando o seu escoamento com rejeitos no rio. Para evitar enchentes em épocas de cheias, degraus de contenção podem ser inseridos criando patamares de diversos níveis de elevação da água. Também há casos em que o rio se encontra canalizado. Para proteger a sua função o ideal é o destamponamento, a renaturalização do leito e a valorização da paisagem do entorno.

\section{Cidadania e cultura}

Objetivo: preservar e valorizar o patrimônio cultural da cidade e criar um elo com o patrimônio ambiental celebrando o rio também como um patrimônio cultural.

Diretrizes:

(a) valorizar a cidade e aproximar as pessoas à natureza; promover o turismo;

(b) incentivar a educação valorizando as características da cidade; e

(c) incentivar a educação ambiental a fim de harmonizar o cidadão com o bem natural.

A criação de um parque linear no entorno do rio, um corredor verde e azul de fácil acesso para pedestres e ciclistas, entra como coadjuvante nessa estratégia, sendo um espaço público que dá a oportunidade para a criação de diversas atividades de recreação e lazer que envolva a sociedade para junto do rio, incentivando-a a adquirir o senso de coletividade e crescimento cultural, como ilustra a Figura 10. Ao estabelecer uma relação de convívio com o rio, a tendência é de que a população passe a tratá-lo de maneira diferente, com mais respeito e cuidado.

\section{Resgate histórico}

Objetivo: resgatar o papel histórico do rio para a cidade a fim de promover a valorização do bem natural.

Diretrizes: expor a história e origens do município aos cidadãos.

Como visto na revisão bibliográfica, os rios urbanos desempenharam um importante papel para o desenvolvimento das cidades, assim como aconteceu em Passo Fundo, porém nem sempre a população possui esse conhecimento. Conhecer a história e a importância que o rio teve e tem para a sua cidade promove uma cultura de valorização desse elemento. A Figura 10 apresenta a sua direita uma praça cultural com monumentos que contam fatos marcantes da história local.

\section{Saúde física e mental}

Objetivo: auxiliar no combate ao sedentarismo e ao estresse atualmente considerados uma epidemia tirando partido dos espaços abertos e da vegetação na cidade e gerando maior contato entre homem e natureza.

Diretrizes: inserir oportunidades para a prática de atividades e para o "escape" da vida contemporânea urbana por meio do contato com a natureza.

Atividades que podem ser inseridas nas áreas verdes, criando espaços convidativos e agradáveis ao longo do percurso do rio, promovendo intuitivamente o contato com a natureza durante a prática de atividades físicas, esportivas e 
sensoriais. Podem ser inseridas pistas de caminhada e corrida, ciclovia, academias ao ar livre, parque infantil, quadras de esportes, espaços zen, espaços contemplativos, entre outros.

\section{Segurança}

Objetivo: melhorar a segurança pública nas áreas do entorno do rio facilitando a aproximação.

Diretrizes: ocupar áreas abandonadas e gerar permeabilidade visual tornando o local atrativo e seguro para a comunidade.

As pessoas não permanecem em locais onde não se sentem seguras, e é justamente a sensação de insegurança que locais abandonados transmitem. Assim, devem-se recriar os espaços ociosos, trazendo uso a eles. Os espaços ocultos e escondidos e espaços sem iluminação adequada devem ser tratados. Em caso da inserção de um parque deve-se considerar também o policiamento constante do local para promover a segurança e também para facilitar a manutenção dos equipamentos urbanos, como mostra a Figura 11.

Assim, dentro de sete diferentes temáticas são propostas estratégias que levam à inserção de um parque urbano para devolver a importância ao rio. Um parque com função ambiental, esportiva, contemplativa, cultural e educacional, com o equilíbrio entre o que é ideal e o que é viável de se implantar na escala urbana da cidade de médio porte, além de ruas verdes que devolvam a permeabilidade no entorno do rio e o conectem, em vez de fragmentar as partes divididas pelas próprias ruas, aproximando as pessoas do corredor verde e azul criado e eliminando o abandono e a insegurança que o vazio causa atualmente.

Na Figura 12 pode-se ter uma visualização do todo o trecho do Rio Passo Fundo estudado e o resultado da inserção das diretrizes propostas como ilustração delas. As estratégias foram inseridas com a criação de um parque linear ao longo do rio e com o manejo das áreas residuais e irregulares.

Figura 10 - Parque linear junto ao rio urbano

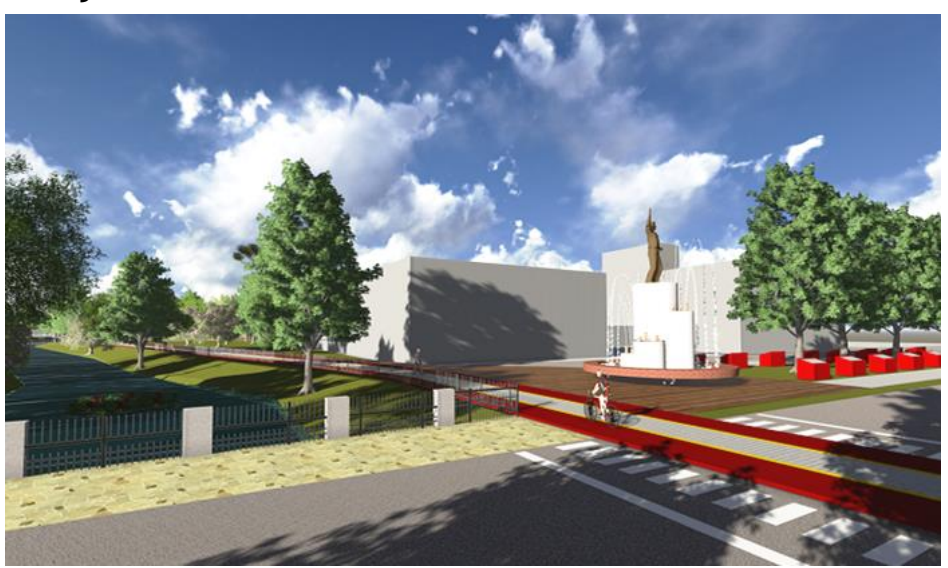

Figura 11 - Parque linear junto ao rio urbano

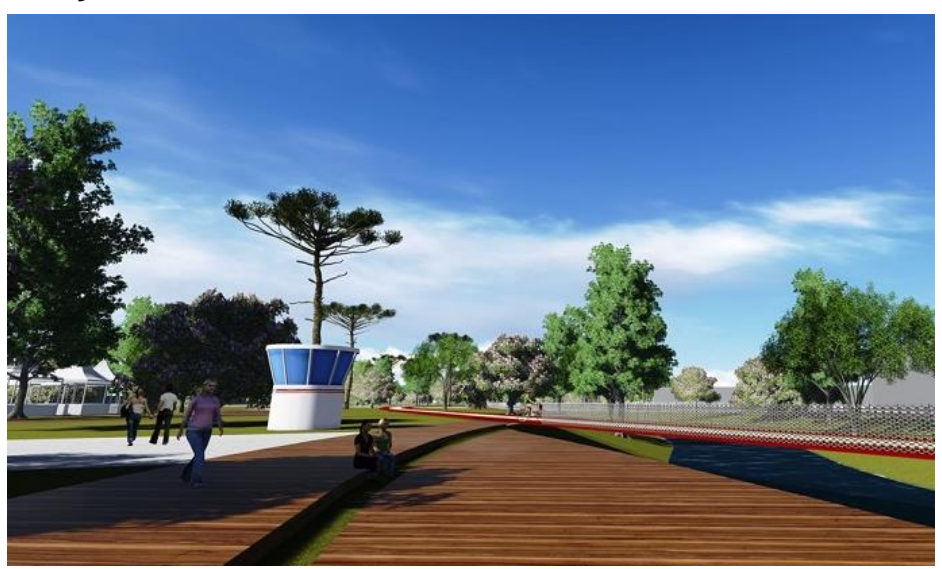

316 Morsch, M. R. S.; Mascaró, J. J.; Pandolfo, A. 
Figura 12 - Antes e depois da inserção das diretrizes propostas

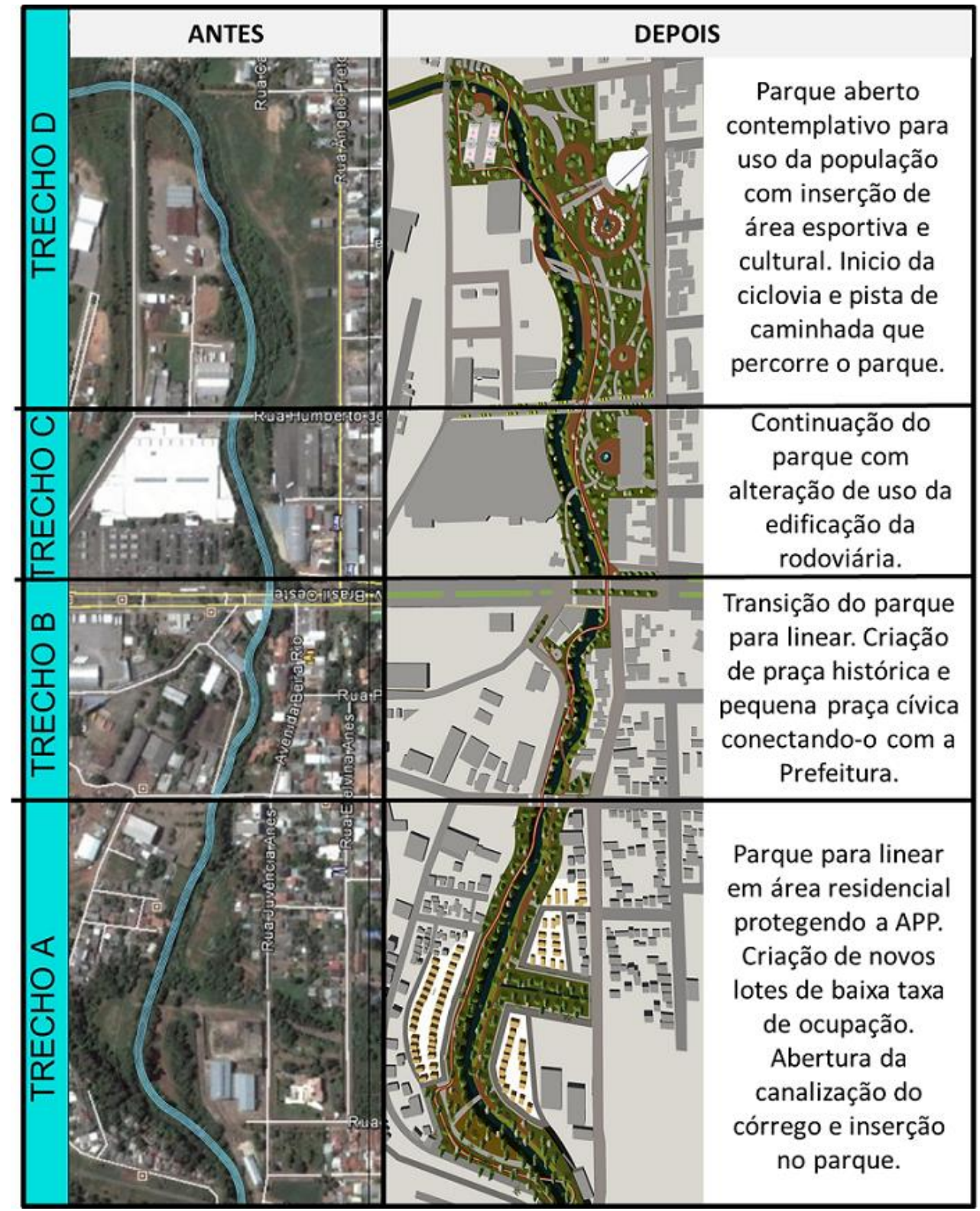

O trecho A tem uma característica residencial e uma grande área de plantação agrícola em torno do rio, o que impossibilita o contato da população com esse meio natural. Para aproximar as pessoas da convivência com a natureza foi proposta a ampliação do bairro com novos lotes residenciais de baixa ocupação e o parque linear na APP do rio, além da abertura do córrego canalizado e a sua conexão com o parque. Devido à característica de moradia e por estar mais afastado do centro, nesse trecho foi reservada uma área para a relocação dos índios, que atualmente vivem nos fundos da rodoviária.

No trecho B, que compreende uma área menor de uso misto onde o rio fica sufocado com a baixa preservação da APP, propôs-se a aplicação de ruas verdes permeáveis nas vias existentes. Nele também se faz um resgate histórico com a releitura de pontos importantes na formação do município. No trecho C inseriu-se um centro de educação ambiental na edificação da rodoviária, que se encontra em local inapropriado, e no trecho D uma biblioteca pública.

Além disso, uma ciclovia e uma pista de caminhada percorrem a margem do rio, equipamentos esportivos e de contemplação para adultos e crianças foram espalhados no parque, e há policiamento e iluminação adequada. Propõe-se também a implantação de infraestrutura verde em todas as ruas em meio e no entorno do parque, fazendo uma conexão das áreas verdes e aumentando a permeabilidade do solo. 
Na seção do rio (Figura 13) pode-se analisar as estratégias propostas para a qualidade da água. Foi proposta a manutenção da vegetação no entorno do rio com arborização de pequeno, médio e grande porte, além do sistema natural de tratamento formado pela zona de sedimentação e de filtragem nas suas margens com inserção de vegetação filtrante. Fez-se uma alteração do perfil do talude existente nas suas margens, criando degraus de contenção de cheias que possuem também a função de aproximar as pessoas ao rio. Além disso, para auxiliar no tratamento do alto nível de poluição, foi proposta a implantação de jardins flutuantes fixados ao longo do rio com plantas filtrantes que se alimentam dos microrganismos presentes na água, fazendo assim a sua purificação.

\section{Conclusão}

No Brasil, mesmo com a vasta demanda hídrica, muitos desconhecem a importância dos rios urbanos. Como mostrou o levantamento realizado, o rio urbano na cidade de Passo Fundo é um espelho do que ocorre em nível nacional, em que pouco se valoriza a paisagem natural, não se controla o lançamento de efluentes e há uma despreocupação com a descaracterização dos cursos d'água. Mostrou também o quanto a sua importância para a cidade, evidenciada ao conhecer os dados históricos do município, foi deixada de lado no decorrer da urbanização. Os rios são um forte elemento natural que carrega consigo a história da cidade, as raízes daquele lugar que a partir dele se transformou.

Reintegrar os rios urbanos na paisagem e fornecer uma relação humana com a água de forma includente são desafios para as cidades brasileiras. As ações de intervenção estão fundamentadas nos princípios conceituais da sustentabilidade e da infraestrutura verde, que visam reestruturar as características do rio urbano. Assim, foram traçados objetivos que visam alcançar todas as vertentes de maneira ecológica e colaborativa, fazendo com que a intervenção alcance diversas funções: técnica, social, econômica, cultural, ecológica e de saúde. A unificação dos sistemas de infraestrutura com o rio urbano e com o parque urbano formou um corredor verde $\mathrm{e}$ azul multifuncional que colabora para a paisagem urbana e para a biodiversidade.

A infraestrutura verde é um elemento fundamental para o desenvolvimento urbano sustentável, proporciona melhor conforto térmico e acústico melhorando o microclima urbano, aumenta a permeabilidade do solo, ajuda na redução considerável nos níveis de $\mathrm{CO}_{2}$, além de embelezar a paisagem da cidade. Os resultados gerados mostram que os espaços naturais degradados podem retomar a sua biodiversidade, o seu apelo ecológico e humano, e assim desenvolver as multifunções da infraestrutura verde em prol da cidade.

\section{Figura 13 - Seção transversal do Rio Passo Fundo no parque urbano proposto}

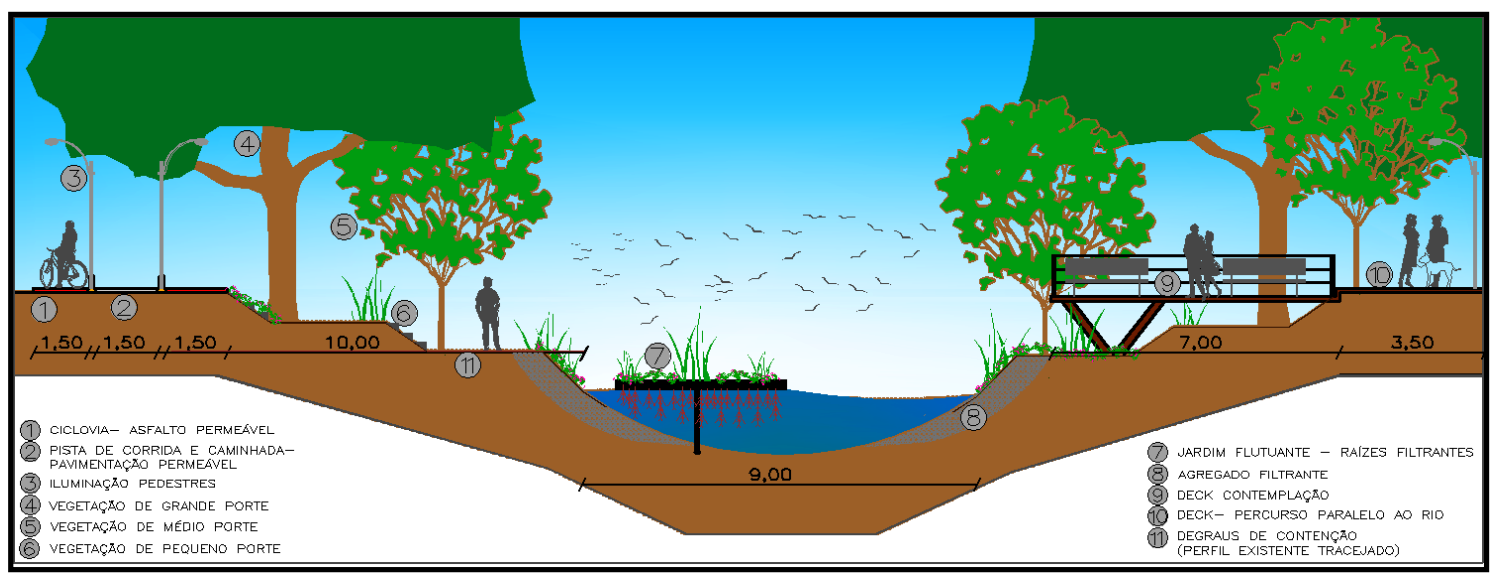

318 Morsch, M. R. S.; Mascaró, J. J.; Pandolfo, A. 
É de grande importância se considerar a recuperação dos rios urbanos de maneira integrada com o desenvolvimento sustentável da cidade. As diretrizes foram geradas devido à relevância dos princípios que são aplicáveis para qualquer caso, destacando-se:

(a) o levantamento físico do rio urbano e de seu entorno com a análise das características físicas, bióticas e antrópicas;

(b) a proteção e regeneração do corpo hídrico com sistemas naturais de tratamento;

(c) a integração dos elementos congênitos com os elementos construídos da cidade;

(d) a valorização da identidade cultural do rio e do município; e

(e) o monitoramento e a gestão das intervenções para garantir o seu funcionamento.

A implantação de práticas ambientais e sociais no meio urbano trazem ganhos significativos para a cidade e para a qualidade de vida das pessoas que ganham espaços de lazer e são incentivadas a praticar a socialização entre si e com o meio. A artificialidade da cidade começa a se harmonizar com os aspectos naturais, ganhando ao melhorar o seu conforto, a qualidade do ar, a permeabilidade e sua salubridade. $\mathrm{O}$ meio ambiente é convidado a participar da rotina urbana de forma equilibrada, com seus elementos vegetais e aquáticos adequados à manutenção da vida ecológica e humana. Esses ganhos podem atingir também a escala regional, uma vez que a água deixa de ser poluída no meio urbano e passa a abastecer a sua bacia hidrográfica com uma melhor qualidade, favorecendo todos que dela dependem para viver.

\section{Referências}

ABELSON, R.; DANKO, J. CH2M HILL \&

Singapore's Canals: reconnecting people to water's life flow. Live Better Magazine, 2013. Disponivel em in:

<http://livebettermagazine.com/article/ch2m-hillsingapores-canals-reconnecting-people-to-waterslife-flow/\#thur>. Acesso em: 15 ago. 2016.

AHERN, J. Greenways in the USA: theory, trends and prospects. In: JONGMAN, R.; PUNGETTI, G. (Eds). Ecological Networks and Greenways: concept, design, implementation. Cambridge: University Press, 2003.

AMORIM FILHO, O. B.; SERRA, R. V. Evolução e Perspectivas do Papel das Cidades Médias no Planejamento Urbano e Regional. In: ANDRADE, T. A.; SERRA, R. V. (Orgs.). Cidades Médias Brasileiras. Rio de Janeiro: IPEA, 2001.
ANDRADE, T. A.; SERRA, R. V. O Desempenho das Cidades Médias no Crescimento Populacional Brasileiro no Período 1970/2000. In: ANDRADE, T. A.; SERRA, R. V. (Orgs.). Cidades Médias Brasileiras. Rio de Janeiro: IPEA, 2001.

BENEDICT, M. A.; MCMAHON, E. T. Green

Infrastructure: linking landscapes and communities. Washington: Island Press, 2006.

BENEDICT, M. A.; MCMAHON, E. T. Green Infrastructure: smart conservation for the $21 \mathrm{st}$ century. Washington, 2004. Sprawl Watch Clearinghouse Monograph Series.

BRACHET, C.; THALMEINEROVA, D. The Handbook for Management and Restoration of Aquatic Ecosystems in River and Lake Basins. Europe, 2015.

BRAGA, R. Cidades Médias e Aglomerações Urbanas no Estado de São Paulo: novas estratégias de gestão territorial. In: ENCONTRO DE GEÓGRAFOS DA AMÉRICA LATINA, 10., São Paulo, 2005. Anais... São Paulo, 2005.

BRITO, F.; HORTA, C. J. G.; AMARAL, E. F. L. A Urbanização Recente no Brasil e as Aglomerações Metropolitanas. Trabalho publicado pela Associação Brasileira de Estudos Populacionais - ABEP - GT Migração, 2001. Disponível em:

<http://www.abep.org.br/usuario/GerenciaNavegac ao.php?caderno_id=362\&nivel=1\&texto_id=2092 >. Acesso em: 18 set. 2014.

COELHO, R. Projectar o Espaço Público na Reconstrução da Cidade Sem Plano: o exemplo da requalificação da Área Central do Cacém. Revista Estudo Prévio, Universidade Autónoma de Lisboa, 2012. Disponível em:

<http://www.estudoprevio.net/artigos/13/rodrigocoelho-.-projectar-o-espaco-publico-nareconstrucao-da-cidade-sem-plano>. Acesso em: 02 jun. 2017.

COMITÊ DE GERENCIAMENTO DA BACIA HIDROGRÁFICA DO RIO PASSO FUNDO. Processo de Planejamento dos Usos da Água Na Bacia Hidrográfica do Rio Passo Fundo Enquadramento Relatório Síntese Final (Rs). Disponível em: <http://www.upf.br/cbhpf/>. Acesso em: 16 set. 2014.

CORAZZA, J. Rios Urbanos e o Processo de Urbanização: o caso de Passo Fundo/RS. Passo Fundo, 2008. Dissertação (Mestrado em Engenharia: Infraestrutura e Meio Ambiente) Escola de Engenharia, Universidade de Passo Fundo, Passo Fundo, 2008. 
COY, M. A Interação Rio-Cidade e a

Revitalização Urbana: experiências europeias e perspectivas para a América Latina. Confins, 2013. Disponível em: 〈http://confins.revues.org/8384〉. Acesso em: 5 nov. 2014.

FERREIRA, J. C. MACHADO, J. R.; InfraEstruturas Verdes Para Um Futuro Urbano Sustentável: o contributo da estrutura ecológica e dos corredores verdes. Revista LABVERDE, São Paulo, v. 1, p. 69-90, set. 2010.

FONTENELLE, R. B. Paris Devolverá a Orla do Sena aos Pedestres. ArchDaily Brasil, 2013. Disponível em:

<http://www.archdaily.com.br/75797/parisdevolvera-a-orla-do-sena-aos-pedestres $>$. Acesso em: 5 nov. 2014.

FUNDAÇÃO ESTADUAL DE PROTEÇÃO AMBIENTAL HENRIQUE LUIZ ROESSLER.

Regiões Hidrográficas do Estado do RS. Disponível em: <http://www.fepam.rs.gov.br/>. Acesso em: 20 set. 2014.

GEHL, J. M. Cidades Para as Pessoas. 2. ed. São Paulo: Perspectiva, 2010.

GOOGLE EARTH. [Mapa]. Disponível em: <https://www.google.com.br/intl/pt-PT/earth/>. Aceso em: 05 ago. 2015.

GUELL, J. M. Planificacion Estratégica de Ciudades: nuevos instrumentos y procesos. Barcelona: Editorial Reverté, 2006.

\section{HERZOG, C. P. Cidades Para Todos:}

(re)aprendendo a conviver com a natureza. Rio de Janeiro: Inverde, 2013.

HERZOG, C. P. Teoria e Prática em Construções Sustentáveis no Brasil. Projeto CCPS. Seção IV: Ambiente Construído. Infraestrutura verde para cidades mais sustentáveis. Rio de Janeiro, 2010.

INSTITUTO BRASILEIRO DE GEOGRAFIA E ESTATISTICA. Censo Demográfico 2010.

Disponível em: <http://www.ibge.gov.br/>. Acesso em: 10 out. 2014.

LE CORBUSIER. Planejamento Urbano. São

Paulo: Perspectiva, 2004.

LEE, K. Cheong Gye Cheon Restoratios Project: a revolution in Seoul. In: ICLEI WORLD

CONGRESS, 2006. Proceedings... 2006.

LITTLE, C. E. Greenways for America.

Baltimore; London: The John Hopkins University Press, 1990.
LOS ANGELES. Los Angeles River

Revitalization, Our River, Our Future.

Disponível em: 〈http://lariver.org〉. Acesso em: 10 out. 2014.

\section{MARCHIONI, M.; SILVA C. O Pavimento}

Intertravado Permeável: melhores práticas. São

Paulo: Associação Brasileira de Cimento Portland, 2011.

MARICATO, E. Brasil, Cidades: alternativas para a crise urbana. Petrópolis: Vozes, 2001.

MARTINELLO, E.; PETRY, C. Arroio Ibirapuitã: a paisagem esquecida. In: FOSCHIRA, E. M.; TEDESCO, C. D. (Orgs.). Educação Para o Cuidado: os múltiplos olhares da educação socioambiental. Rio de Janeiro: Multifoco, 2013.

MELL, I. C. Making Paris Greener: the use of green infrastructure in promoting Paris as an attractive and multi-functional city. Disponível em: <http://www.academia.edu/4981993/Making_Paris _Greener>. Aceso em: 02 jun. 2017.

MELO, O. V. O Rio Que Serviu de Lazer e Integração. Diário da Manhã, Passo Fundo, suplemento, p. 6, 21 nov. 1998.

MINKS, V. A Rede de Design Verde Urbano: uma alternativa Sustentável para megacidades? Revista LABVERDE, São Paulo, v. 7, p. 120-141, dez. 2013.

MUMFORD, L. A Cidade na História. São Paulo: Martins Fontes, 1998.

OLIVEIRA, L.; MASCARÓ, J. J. Análise da Qualidade de Vida Sob a Ótica dos Espaços Públicos de Lazer. Ambiente Construído, Porto Alegre, v. 7, n. 2, p. 21-31, abr./jun. 2007.

PELLEGRINO, P. et al. A Paisagem da Borda: uma estratégia para a condução das águas, da biodiversidade e das pessoas. In: COSTA, L. M. S. A. (Org.). Rios e Paisagem Urbana em Cidades Brasileiras. Rio de Janeiro: Viana \& Mosley Editora; Editora PROURB, 2006.

PLATAFORMA URBANA. Proyecto Río la Piedad y Ciudad Deportiva prometen devolver al D.F. su relación con el agua. Disponível em: <http://www.plataformaurbana.cl/archive/2013/12/ 31/proyecto-rio-la-piedad-y-ciudad-deportivaprometen-devolver-al-d-f-su-relacion-con-elagua/>. Acesso em: 10 out. 2014.

PORATH, S. L. A Paisagem dos Rios Urbanos: a presença do Rio Itajaí-Açu na cidade de Blumenau. Florianópolis, 2003. Dissertação (Mestrado em Arquitetura e Urbanismo) - Escola de Arquitetura e Urbanismo, Universidade Federal de Santa Catarina, Florianópolis, 2003. 
PREFEITURA MUNICIPAL DE PASSO

FUNDO. Mapa de Passo Fundo. Passo Fundo, 2015.

\section{REGISTER, R. Conceito de Cidade Ecológica Busca Evitar o Caos Urbano. 1996.}

RISCO. Espaço Público do Cacém. Disponivel em: 〈http://www.risco.org/pt/02_04_cacem.jsp\#>. Acesso em: 19 set. 2015.

SILVA, G. J. A. ROMERO, M. A. B. O Urbanismo Sustentável no Brasil: a revisão de conceitos urbanos para o século XXI: parte 02 . Arquitextos, São Paulo, 2011, Vitruvius. Disponível em: <http://www.vitruvius.com.br/revistas/read/arquite xtos/11.128/3724>. Acesso em: 01 set. 2014.
VEGARA, A. Territorios Inteligentes: nuevos horizontes en el urbanismo. Metrópolis em Revista, v.4, n.1, p. 61-68, 2002.

YONG, J.; TAN, S. N.; Improving Water Quality Through Water Plants. Innovation in Water Singapore. PUB, June, 2014. Disponível em: <https://www.pub.gov.sg/Documents/Vol_6.pdf>. Acesso em: 19 ago. 2016.

\section{ZEIN, D. Turenscape Design Outsdanding}

River Park: The Floating Gardens by Turenscape. Landscape Architects Network. Disponível em: $<$ http://landarchs.com/turenscape-designoutstanding-river-park/>. Acesso em: 10 out. 2014.

\section{Maiara Roberta Santos Morsch}

Departamento de Arquitetura e Urbanismo, Faculdade de Engenharia e Arquitetura | Universidade de Passo Fundo | Campus 1, Bairro São José | Passo Fundo - RS - Brasil | Caixa Postal 566 | CEP 99001-970 |Tel.: (54) 3316-8100 | E-mail: arq.maiaramorsch@gmail.com

\section{Juan José Mascaró}

Departamento de Arquitetura e Urbanismo, Faculdade de Engenharia e Arquitetura | Universidade de Passo Fundo | Tel.: (54) 316-8201 Ramal 185 | E-mail: juan@upf.br

\section{Adalberto Pandolfo}

Faculdade de Engenharia e Arquitetura | Universidade de Passo Fundo | Tel.: (54) 9165-8826 | E-mail: adalbertopandolfo@hotmail.com

Revista Ambiente Construído

Associação Nacional de Tecnologia do Ambiente Construído

Av. Osvaldo Aranha, $99-3^{\circ}$ andar, Centro

Porto Alegre - RS - Brasil CEP $90035-190$

Telefone: +55 (51) 3308-4084

Fax: +55 (51) 3308-4054

www.seer.ufrgs.br/ambienteconstruido

E-mail: ambienteconstruido@ufrgs.br 